\title{
USE OF BLOOD AND BLOOD COMPONENTS IN DHAKA MEDICAL COLLEGE HOSPITAL
}

\author{
FAHMIDA SHARMIN CHOWDHURY ${ }^{1}$, MD. ALI EHSAN SIDDIQUI ${ }^{2}$, KHAIRUL ISLAM ${ }^{3}$, ZUBAIDA NASREEN $^{4}$, \\ HUSNE ARA BEGUM ${ }^{5}$, HOSNE ARA BEGUM ${ }^{6}$
}

\begin{abstract}
Introduction: Use of blood means providing the right blood product, in the right quantity, for the right patient. It can help in bridging the gap between demand and supply of the precious blood or blood products.

Objective: The present study was designed to study appropriateness of use of the blood components in different wards in $\mathrm{DMCH}$, to improve the consistency and appropriateness of transfusion practice, to promote the integration of quality management systems into transfusion practice, to reduce the overall number of transfusion-related complications, to increase consumer awareness of the benefits and risks of blood component therapy; and conserve a limited resource.

Methodology: This study was done at Transfusion Medicine Department of Dhaka Medical College Hospital in the period between January 2008 to December 2011. Donors of 18 to 55 years of both sexes were selected after reviewing the questionnaire, physical and medical examination and written consent. Blood was collected in different blood bags. Blood components were prepared by centrifugation of whole blood in a refrigerated centrifuge machine. Data was collected using a pretested questionnaire on age, gender, department, haemoglobin levels, indications of blood transfusions, types of product advised, total number of units ordered, cross-matched and transfused. Rational use of blood was assessed by determining prevalence of appropriateness using World Health Organisation's clinical practical guidelines and transfusion indices. Interviews were done with doctors to assess their knowledge and practices.
\end{abstract}

Result: In 2008, 1231(8.4\%) components were prepared against 14560 whole blood. In 2009, 1636 (9.63\%) components against 16984 whole blood were prepared. In 2010, 1380 (8.13\%) components were prepared against 16980 whole blood. In 20111800 (8.91\%) components were prepared and supplied to surgery, medicine, gynae, paediatrics, haematology and oncology wards.

Conclusion: The hospital was not rationale in use of blood.

Key words: Components therapy, RCC, FFP, PRP, PC, Cryoprecipitate.

Received: 10 January 2014

Accepted: 19 October 2014

\section{Introduction}

All patients requiring transfusion should have reliable access to safe blood products, including whole blood, labile blood components and plasma-derived medicinal products, appropriate to their clinical needs, provided in time and safely administered. Data on the use of blood products are limited, but studies suggest that blood products are often overprescribed in both developed and developing countries. ${ }^{1}$
This is the separation of whole blood into its individual components to optimize individual therapeutic potency based on sound physiologic principles and understanding of the relative risks and benefits of each transfusion. ${ }^{2}$

Component therapy introduced within 1950's-1960. This therapy involves administering only the component needed, i,e. the "minimum for the

1. Asso. prof. Transfusion Medicine, NIKDU, Dhaka

2. Consultant, Cardiology, NITOR, Dhaka

3. Asst. Prof. Transfusion Medicine, NITOR, Dhaka

4. MO. Transfusion Medicine, $\mathrm{DMCH}$, Dhaka

5. Prof. Transfusion Medicine, DMC, Dhaka

6. Asso. Prof. Transfusion Medicine, DMC, Dhaka

Correspondence: Dr. Fahmida Sharmin Chowdhury, Asso. Prof., Transfusion Medicine, NIKDU, E-mail: drmdaliehsan@g mail.com

Bangladesh J Medicine 2015; 26 : 18-24 
maximum". The clinical practice guidelines for the use of blood components aim to: improve the consistency and appropriateness of transfusion practice; promote the integration of quality management systems into transfusion practice; reduce the overall number of transfusion-related complications; increase consumer awareness of the benefits and risks of blood component therapy; and conserve a limited resource. ${ }^{3}$

Merits of components transfusion: Overload avoided, greater shelf life than whole blood, blood shortage can be overcome for better patient management. ${ }^{4}$ Optimal utilization of blood helps in reducing or eliminating the use of allogenic blood and often prevents unnecessary exposure of a patient to the risk of blood-borne endogenous infections. Appropriate and rational use of blood/blood components is required to ensure their availability to needy patients as well as to avoid the unnecessary risk of transfusion-transmitted diseases. 5

\section{Commonly used components are: 6}

Red Cell Concentrate (RCC)

- Leukocyte-Reduced

- Washed

- Frozen, Deglycerolized

- Irradied

Platelets Concentrate (PC)

- Plateletpheresis

- Platelet concentrates

Granulocytes

Fresh plasma (FP)

Fresh frozen plasma (FFP)

Platelet Rich Plasma (PRP)

Liquid Plasma

Cryoprecipitate

Cryoprecipitate reduced plasma

\section{Red Cell Concentrate: ${ }^{7}$}

150 to $200 \mathrm{ml}$ red cells after removing plasma from 1 unit of whole blood. Hb approx $20 \mathrm{gm}$ per $100 \mathrm{ml}$. Stored at +2 to $+6^{\circ} \mathrm{C}$ in blood bank refrigerator for $21,28,35$, or 42 days depending on preservative or additive. Used in replacement of red cells in anemic patient, chronic anemia, congenital hemolytic anemia, oncology patients (chemo/radiation), cardiac, orthopedic, and other surgery, end-stage renal disease, premature infants. Transfusion should be started within $30 \mathrm{~min}$ of removal from refrigerator. Must be $\mathrm{ABO}$ and $\mathrm{Rh}$ compatible. Should be completed within 2 hrs 30 mins. In non urgent settings, transfuse one unit at a time. For infant, 5 to $10 \mathrm{ml} / \mathrm{kg}$. One unit increases $\mathrm{Hb} 1 \mathrm{~g} / \mathrm{dL}$ and hematocrit by $3 \%$ in a $70 \mathrm{~kg}$ adult.
RCC Types: ${ }^{8}$

RCC (frozen): d" $-65^{\circ} \mathrm{C}$ for 10 years. Used in patient with multiple red cell antibodies, needing rare blood type, autologous red cells for patients with antibodies to high frequency antigens.

RCC (washed): Good at $1-6^{\circ} \mathrm{C}$ for 24 hours. Used in patients with IgA deficiency and antibodies to IgA, patient with haptoglobin deficiency and antibodies to haptoglobin, patients with severe transfusion reactions to plasma proteins unresponsive to medications.

RCC(Leukocyte depleted): Reduces the rate of febrile non-hemolytic transfusion reaction, prevent CMV transmission, delay or prevent development of platelet transfusion refractoriness due to HLA antibodies with hematological malignancies or aplastic anaemia, may prevent HLA sensitization in bone marrow, peripheral stem cell, cord blood and solid organ transplantation.

RCC (irradiated): $1-6^{\circ} \mathrm{C}$ for 28 days. Irradiation of cellular blood components containing viable lymphocytes is performed to prevent transfusion associated graft-versus-host disease in patient with profound immunodeficiency or suppression.

\section{Platelet Concentrate: ${ }^{8}$}

Single donor unit in a vol. of $50-60 \mathrm{ml}$ plasma containing at least $55 \times 10^{9}$ platelet. Pooled unit (4-6 donor) containing $240 \times 10^{9}$ platelet. Stored upto 4-5 days at 22-24p C with agitation in special bag. Used in treatment of bleeding due to thrombocytopenia, platelet function defects and prevention of bleeding due to thrombocytopenia, e.g. bone marrow failure, some inherited or acquired platelet function disorders depending on clinical features and setting, primary immune thrombocytopenia (ITP) with life threatening bleeding or before splenectomy with platelet count $<10$ x $10^{9} / \mathrm{L}$, disseminated intravascular coagulation with platelet count $<50 \times 10^{9} / \mathrm{L}$. Volume of random donor platelets (RDP) is $50-60 \mathrm{ml}$ and apheresis platelet approximately $250 \mathrm{ml}$. A pool of 5-6 concentrates is therapeutically equivalent to a plateletpheresis. The FDA guideline dictate that pheresis platelets must contain $>300 \times 10^{9}$ platelets ( 6 equivalent units), or $>55 \times 10^{9}$ in platelet concentrate prepared from units of whole blood. Transfusing a pool of 5 conc. or a plateletpheresis should increase an adult's platelet count by $25-50 \times 10^{9} / \mathrm{L}$ in absence of consumption. Increment will be less if there is splenomegaly, DIC, septicemia. After pooling, platelet conc. should be infused as soon as possible, generally within $4 \mathrm{hrs}$. Must not refrigerated before infusion. Should be infused over $30 \mathrm{~min}$. 
Fresh Plasma (FP), Platelet Rich Plasma (PRP), Fresh frozen plasma $(\mathrm{FFP}):^{8}$

Plasma separated from whole blood within 6 hrs of collection is called fresh plasma and platelet rich plasma. Plasma separated from whole blood within 6 hrs of collection and then rapidly frozen to $-25 \mathrm{p} \mathrm{C}$ or colder is called fresh frozen plasma. Contain noncellular portion of blood, including fibrinogen (200$400 \mathrm{mg}$ per unit), antithrombin III, factors V and VIII (0.7 IU per $\mathrm{ml}$ ), albumin and globulin. Usual vol. 200 - $300 \mathrm{ml}$. Stored at $-25 \mathrm{p} \mathrm{C}$ or colder for 1 year. Used for replacement of multiple clotting factor deficiency, DIC, TTP, deficiencies of other isolated plasma proteins and factors where concentrates are not readily available (antithrombin, protein $\mathrm{C}$ and protein $\mathrm{S}$ deficiencies), antithrombin III deficiency in a patient requiring heparin, therapy of acute angioedema, preoperative prophylaxis in hereditary $\mathrm{C} 1$-inhibitor deficiency, reversal of warfarin therapy, massive blood transfusion. FFP is thawed before transfusion at 30$37^{\circ} \mathrm{C}$ water bath for $30-45$ minutes. Stored at +2 to $+6^{\circ} \mathrm{C}$ and transfused within 24 hours. Labile factors rapidly degrade; use within 6 hrs of thawing. Dose is $10-20 \mathrm{ml} / \mathrm{kg}$ body weight. In a adult, each unit will increase the activity of plasma clotting factors by about $4 \%-5 \%$ and fibrinogen by about $10 \mathrm{mg} / \mathrm{kg}$. If the PTT is less than 45 seconds or INR less than 1.5 , plasma transfusion is rarely indicated.

\section{Cryoprecipitate: ${ }^{8}$}

Prepared from FFP after thawing at $+4 \mathrm{p} \mathrm{C}$. Contain factor VIII (80-120 units), fibrinogen (150-250 mg), von Willebrand factor (40-70\%), Factor XIII (20-30\%) and fibronectin. Volume is approximately $5-20 \mathrm{ml}$. Stored at $-25 \mathrm{p} \mathrm{C}$ or colder for 1 year. Used in factor VIII deficiency (Hemophilia A), factor IX deficiency (Hemophilia B), von Willebrand's Disease, congenital or acquired fibrinogen defects (i.e., dysfibrinogenemia). Indicated for bleeding associated with fibrinogen level $<100 \mathrm{mg} / \mathrm{dL}$ and Factor XIII deficiency.Usual dose is one cryoprecipitate unit per $10 \mathrm{~kg}$ of body weight.

In the absence of heavy consumption or bleeding one unit of cryoprecipitate per $10 \mathrm{~kg}$ of body weight raises plasma fibrinogen concentration by 40 - $50 \mathrm{mg} / \mathrm{dL}$. One unit will increase Factor VIII activity by about $4 \%$ and fibrinogen by about $7-10 \mathrm{mg} / \mathrm{dL}$ in a $70 \mathrm{~kg}$ adult. Must be transfused within 6 hrs of thawing.
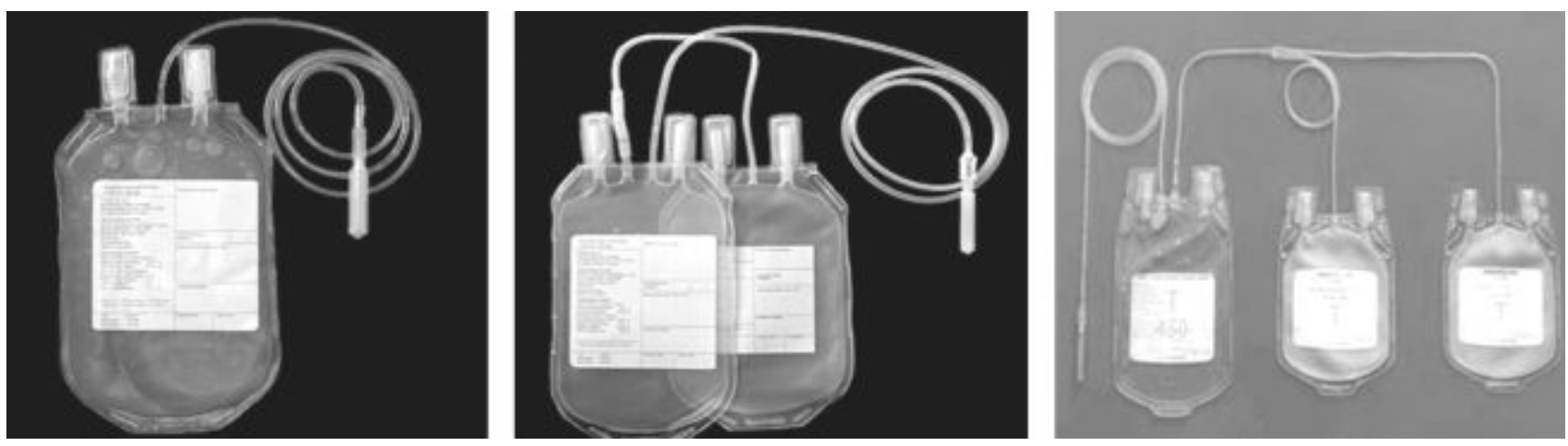

Fig.-1: Blood bags used for component preparation. STEPS OF BLOOD COMPONENTS PREPARATION

\section{Cryoprecipitate reduced plasma: ${ }^{8}$}

Approximately $300 \mathrm{ml}$ per unit. Commonly called cryopoor plasma that has been depleted of cryoprepitable protein. It is used for patient with TTP requiring plasma exchange.

\section{Granulocyte concentrate: 8}

Usual volume is $150-300 \mathrm{ml}$. Contain $2-3 \times 10^{10}$. Used for patient with infections unlikely to respond to high dose of antibiotic.

\section{Methodology}

This observational study was done in Transfusion Medicine Department of Dhaka Medical College Hospital between the period of January 2008 to December 2011. Donors of 18 to 60 years of both sexes were selected after reviewing the questionnaire,

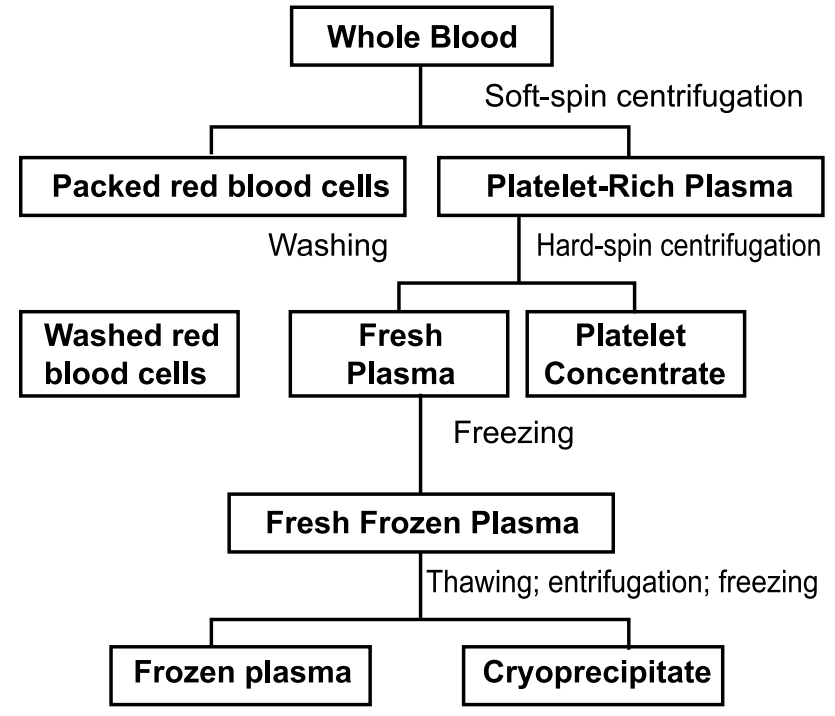


physical and medical examination and written consent Certain additional and specific conditions. have to be met when separating whole blood into components. Aspirin or Aspirin containing compounds depress platelet function for 1 to 5 days. Therefore, blood collected from a donor with Aspirin intake within five days prior to donation was not only source of platelet concentrate for a particular patient. Approximately $450 \mathrm{ml}$ blood is collected in a sterile pyrogen free multiple plastic bag system with integral tubing in a closed system. Donation of one unit of whole blood ideally should not be more than 10 minutes. If duration is more than 15 minutes, the plasma was not used for preparation of platelet or plasma. Immediately after collection, the tube was sealed, all the satellite bags were identified and numbered and labeled as on original unit. The blood was processed for component preparation within 6 hours of collection. Meanwhile it was stored at $2^{\circ} \mathrm{C}$ to $6^{\circ} \mathrm{C}$ except for the preparation of platelets, in which case, it was stored at $22^{\circ} \mathrm{C}$ to $24^{\circ} \mathrm{C}$. For pooling, saline washing and other open system processing, aseptic techniques and pyrogen free equipments were used. Blood components were prepared by centrifugation of whole blood in a refrigerated centrifuge machine, which results in sedimentation of various blood components into the different layers depending on their size and density. Thus, the red cells are at the bottom, leucocytes at the top of the red cell mass; next the platelets and lastly, the plasma in the upper part of the bag. After the first centrifugation, the primary bag is placed in a plasma extraction system and the layers are transferred one by one, into satellite bags within the closed system. For platelet preparations, centrifugation is done at $22^{\circ} \mathrm{C}$ and for all other products at $4^{\circ} \mathrm{C}$. Red cell units are stored at $4^{\circ} \mathrm{C}$. Platelet rich plasma further centrifuged to prepare platelet concentrates to be stored at room temperature and plasma stored in a frozen condition. $^{9}$ Data was collected using a pre-tested questionnaire on age, gender, department, haemoglobin levels, indications of blood transfusions, types of product advised, total number of units ordered, cross-matched and transfused. Rational use of blood was assessed by determining prevalence of appropriateness using World Health Organisation \'s clinical practical guidelines and transfusion indices. Interviews were done with doctors to assess their knowledge and practices.

\section{Results}

Results were arranged at tables.

Table I

No. of whole blood collected vs No. of component prepared

\begin{tabular}{lccc}
\hline Period & $\begin{array}{c}\text { No. of unit } \\
\text { collected }\end{array}$ & $\begin{array}{c}\text { No. of component } \\
\text { prepared }\end{array}$ & $\%$ \\
\hline 2008 & 14560 & 1231 & 8.45 \\
2009 & 16984 & 1636 & 9.63 \\
2010 & 16980 & 1380 & 8.13 \\
2011 & 20202 & 1800 & 8.91 \\
Total & 68726 & 6047 & 8.79 \\
\hline
\end{tabular}

Table II

Component prepared yearly

\begin{tabular}{llccc}
\hline Period & RCC & Plasma & PRP & PC \\
\hline 2008 & 522 & 504 & 18 & 187 \\
2009 & 762 & 762 & 00 & 112 \\
2010 & 623 & 605 & 18 & 134 \\
2011 & 790 & 760 & 30 & 220 \\
Total & 2697 & 2631 & 66 & 653 \\
\hline
\end{tabular}

Table III

Use of RCC in different department

\begin{tabular}{lcc}
\hline Department & No. of unit & $\%$ \\
\hline Haematology & 1267 & 46.98 \\
Onchology & 1133 & 42.01 \\
Nephrology & 189 & 07.01 \\
Obstetric & 108 & 04.00 \\
\hline Total & 2697 & 100.00 \\
\hline
\end{tabular}

Table IV

Use of Plasma in different department

\begin{tabular}{lcc}
\hline Department & No. of unit & $\%$ \\
\hline Burn & 2050 & 77.91 \\
Hepatology & 497 & 18.89 \\
Obstetric & 127 & 4.83 \\
Paediatric & 57 & 2.17 \\
\hline Total & 2631 & 100.00 \\
\hline
\end{tabular}

Table V

Use of PRP in different department

\begin{tabular}{lcc}
\hline Department & No. of unit & $\%$ \\
\hline Medicine (dengu) & 57 & 86.36 \\
Obstetric (DIC) & 09 & 13.64 \\
\hline Total & 66 & 100.00 \\
\hline
\end{tabular}


Table VI

Use of PC in different department

\begin{tabular}{lcc}
\hline Department & No. of unit & $\%$ \\
\hline Medicine (dengu) & 355 & 54.36 \\
Haematology & 256 & 39.20 \\
Obstetric & 42 & 6.44 \\
Total & 653 & 100.00 \\
\hline
\end{tabular}

\section{Discussion}

Blood transfusions are a common practice in hospital settings. However, rational use of blood transfusion remains variable among healthcare institutions and patient populations. Despite mounting evidence demonstrating significant harm from unnecessary blood transfusions, results of several studies conducted in developed countries documented a generalised lack of compliance with appropriate transfusion guidelines as well as tremendous variation in transfusion practice among different institutions and among individual physicians within the same institution.

The objective of the study was to assess rational use of blood and blood products in various departments in $\mathrm{DMCH}$, determining the prevalence of appropriate use of blood and blood products; determining blood cross-match ordering practices; and assessing the knowledge and practices of physicians about the rational use of blood and blood products.

In $2008,1231(8.4 \%)$ components were prepared against 14560 whole blood. In 2009, 1636 (9.63\%) components against 16984 whole blood were prepared. In $2010,1380(8.13 \%)$ components were prepared against 16980 whole blood. In 2011 ,1800 (8.91\%) components were prepared and supplied to surgery, medicine, gynae, paediatrics, haematology and oncology wards. Study showed that whole blood transfused more (91\%-92\%) than components $(8 \%-$ $9 \%)$. Only department of hematology made irregular follow up of some patient by $\mathrm{Hb} \%$, platelet count, clotting factor assay. So data about appropriate use could not be collected. Again in Dengu shock syndrome platelet concentrate used more than platelet rich plasma. Although platelet rich plasma is more beneficial.

As per the WHO criteria, 6-16 units (average of 11 units) of blood are required per hospital bed. In Pakistan at the existing level shortage amounts to as much as $40 \% .{ }^{11}$ The problem is further compounded by inappropriate use of blood which is up to $25 \%$ without separation into its components, with $80-85 \%$ of blood being used as whole blood. ${ }^{12-14}$
According to the International Red Cross, if blood was used more appropriately, the number of transfusions could be brought down by $30 \% .^{15}$

$\mathrm{WHO}^{16}$ strongly discourages single-unit transfusions in adults and, hence, clinical practice is now dominated by two-unit transfusions. Thus, many units of blood routinely ordered are not utilized, but are held in reserve, loss of shelf life and wastage of blood. ${ }^{17}$ In the absence of an explicit maximum blood order policy in hospitals, ordering for blood transfusion is frequently based on subjective anticipation of blood loss instead of evidence-based estimates of average requirement in a particular procedure. Implementation of maximum surgical blood ordering schedule (MSBOS) can result in about 60\% reduction of cost to the patient. ${ }^{18}$

Rational use of blood implies that right blood product is to be given to the patient only when needed and in the right amount. ${ }^{19}$ Therefore, it is essential to look into the existing blood transfusion practices and collect background information about the type of existing blood transfusion practices e.g. requests for single-unit transfusion, fresh blood transfusion, use of whole blood etc. in a hospital setting. .

In the public hospital of pakistan, appropriate use of blood was only $54.1 \%(n=92)$ as compared to the private hospital where the appropriateness was $69.4 \%(n=125)$. The cross-matched-to-transfusion ratio was 1.1 and 2.7 , where transfusion index was 2.6 and 2.5 in public and private hospital respectively. Doctors had good clinical knowledge, but were not using any guidelines. ${ }^{20}$

It was found that criteria for appropriate transfusion were fulfilled by $54 \%$ in the public and $69 \%$ in the private hospital. This finding was, however, lower compared to previous studies conducted in other hospitals in Pakistan where appropriate transfusions were $80-85 \%$ but in those studies no standard guidelines had been used or at least not mentioned in the methodology.Even in developed countries $^{21}$ inappropriate transfusion is in the range of $18-35 \%$, while in India the range varied from $30 \%$ to $60 \%{ }^{22,23}$ which is almost the same as in this study.

The limited available information from developing countries also suggests that blood transfusion practices are not in accordance with international guidelines for safe and rational use of blood transfusions. Doctors do not consistently follow any standard guidelines and base their decision to transfuse on anticipated blood loss, past experience, subjective personal judgment, misconceptions, myths and prescribing by habit. ${ }^{24-26}$ 
Most indications for whole blood transfusion are now well-managed exclusively with blood component therapy, yet the use of fresh whole blood was still seen in the public hospital on a routine basis, when there was no compelling evidence for the use of whole blood in preference to component therapy for its routine. ${ }^{27}$ It is similar to this study. At DMCH $91 \%$ $92 \%$ whole blood were transfused and transfusing. The rate of component preparation and transfusion is very poor, only $8 \%-9 \%$.

Rational use of blood implies that blood is to be given to the patient only when needed. As per the WHO criteria, 6-16 units (Average. 11 units) of blood are required per hospital bed. This works out to be 60 Lakh units per year for India. At the existing level shortage amounts to as much as $60 \%$, and at the same time unnecessary transfusions range between $30 \%$ to $60 \% .^{28}$

Of the total 184 episodes of blood component transfusions, $153(83.1 \%)$ episodes were appropriate and $31(16.9 \%)$ episodes were inappropriate. Among these, fresh frozen plasma transfusions had highest inappropriate $[18 / 41(58 \%)]$ episodes followed by packed red cell transfusions $[11 / 110(35.5 \%)]$ and platelet transfusions $[2 / 5(6.45 \%)]$. There was no inappropriate episode of cryoprecipitate transfusion. ${ }^{29}$

Practices regarding transfusion of single and multiple units of blood and its components revealed that single unit transfusion was seen in all departments of the hospitals. Although $\mathrm{WHO}^{11}$ suggests that there is no benefit in transfusing 1 unit of RCC, as it is insufficient to correct anaemia. A study conducted in Canada to address the role of single-unit transfusions as a blood-saving technique revealed that a singleunit transfusion strategy could be an effective, simple, practical and cost-saving method of reducing the risks associated with allogenic blood exposure. Transfusion of a single unit should not be considered inappropriate by itself. However, its use without appropriate clinical judgment is not acceptable. In a country like Bangladesh, where there are resource constraints, the use of single-unit transfusion can thus be acceptable.

There is need to change attitudes and orientation. It does not require large capital or technology. Moreover, this basic approach of collecting representative data of current practices may be a useful first step towards improving rational use of blood. It is high time for Bangladesh to implement policies towards educating doctors regarding current practices in blood transfusion. Frequent audit of transfusion practices is highly needed. Compliance with standard guidelines can reduce unnecessary costs to hospitals and patients and the well-known risks of blood transfusion. Strict clinical governance by senior physicians and external quality checks are necessary to modify physicians' behaviour in ordering unnecessary transfusions. By developing and implementing comprehensive blood management programmes focusing on implementation of evidencebased transfusion guidelines to reduce variability in transfusion practice in hospitals can promote safe and clinically effective blood utilisation.

\section{Conclusion}

The present study reinforces the importance of blood audit in the clinical setting. Judicious implementation of guidelines for use of various blood products may help to decrease the inappropriate use of blood components. Regular transfusion audit can thus alter clinical practice which may also translate into risk reduction.

One unit of blood can save many. Safe blood product, use correctly, can be life saving.

\section{Reommendation}

It is the duty of the official at the blood bank to ensure that transfusions are rational. It is recommended that transfusion practices can be improved and made rational by increasing the capacity of the blood bank, by the availability of facilities for component therapy preparation and storage. Blood bank should create awareness among doctors about component use and should also create awareness in general public that it is very essential to donate blood and it does not do any harm to the donor.

\section{Acknowledgement}

Sincerest thanks are extended to the administration and blood bank staff of the hospitals for their cooperation and assistance.

\section{References}

1. World Health Organization, Blood Transfusion Safety, Safe and rational clinical use of blood, URL:http:/ / www.emro.who.int/programmeareas_ bloodsafety.htm.

2. Schenk J.F. · Stephan B. Mörsdorf S. Tilev K. Krischek B. Wenzel E. Trümper L. Rational Use of Blood and Blood Components in Hematology and Oncology, TRANSFUSION MEDICINE AND HAEMATOLOGY 2000; Vol. 27, No. 4, 2000

3. The NHMRC/Australasian Society of Blood Transfusion (ASBT) Clinical Practice Guidelines on the Use of Blood Components (2001)

4. B.G Solheim, F Wesenbe. Rationale Use Of Blood Journal of Cancer, Volume 37, Issue 18, December 2001, Pages 2421-2425. 
5. Rationale use of blood product, European Journal of Cancer ,2001; 37(18) : 2421-2425.

6. Mollison P.L., Engelfriet C.P., Conteras M. Blood Transfusion in Clinical Medicine. Oxford: Blackwell Scientific Publications; 1993.

7. World Health Organization, The Clinial Use Of Blood.p;2 1-32

8. Blood Component Transfusion Guidelines For Transfusing Physician .Handbook of Blood Bonking and Transfusion Medicine, Jaypee Brothers Medical Publishers Ltd ,new Delhi,2006,P:122-145.

9. World Health Organization. Blood Safety: Situation analysis. (Online) 2008 (Cited 2008 Jan 25). Available from URL:http://www.emro.who.int/ pakistan/programmeareas_bloodsafety.htm.

10. Organization and Preparation of a Regional blood Transfusion Center in India. Handbook of Blood Bonking and Transfusion Medicine, Jaypee Brothers Medical Publishers Ltd ,new Delhi,2006,P:11-28.

11. World Health Organization. World blood donor day, Pakistan. (Online) 2008 (Cited 2008 Jun 16). Available from URL:http://www.who.int/world blood donorday/archives/2006/wbdd_pakistan/en/ index.html

12. Kanwal S, Jabeen K, Afghan S, Rashid R, Mazher BS. Current blood transfusion practices in obstetrics \& gynaecology at $\mathrm{MCH}$ Centre PIMS. Ann Pak Inst Med Sci 2005; 1: 238-41.

13. Ahmed P, Khan BA, Dilawar M, Mahmood A. Blood Transfusion: A Retrospective study at Combined Military Hospital, Multan. Pak Armed Forces Med J 2000; 50: 76-80.

14. Naeem MA, Masood A, Nuzhat M, Farhat AB: Evaluation of red cell transfusion triggers. Pakistan J Pathol 2006; 17: 56-9.

15. Sharma R.South East Asia faces severe shortage of safe blood. BMJ 2000; 320: 1026.

16 World Health Organization. Blood safety and clinical technology: Strategy for Safe Blood Transfusion, Promoting and Practicing Rational Use of Blood. (Online) 2008 (Cited 2008 Jan 28). Available from URL:http:/ /www.searo.who.int/EN/Section 10/ Section $17 /$ Section53/Section478_1675.htm\# Practising.

17. Jayaranee S, Prathiba R, Vasanthi N, Lopez CG. An analysis of blood utilization for elective surgery in a tertiary medical centre in Malaysia. Malays $\mathrm{J}$ Pathol 2002;24:59-66.

18. Chawla T, Kakepoto GN, Khan MA. An audit of blood cross-match ordering practices at the Aga Khan University Hospital: first step towards a Maximum Surgical Blood Ordering Schedule. J Pak Med Assoc 2001; 51: 251-4.

19. Ma M, Eckert K, Ralley F, Chin-Yee I. A retrospective study evaluating single-unit red blood cell transfusions in reducing allogeneic blood exposure. Transfusion Med 2005; 15: 307-12.

20. Sabeen Afzal (A comparison of public and private hospital on rational use of blood in Islamabad Journal Of Pakistan Medical Association, January 2003

21. The Northern Ireland Regional transfusion committee. Regional appropriateness of blood transfusion audit, summary report, 2004.

22. Fazili F. Special Focus: Blood Safety and Rational Use of Blood. Ind $\mathrm{J}$ Practising Doctor 2006; 3 : 2006-4.

23. Nira GJ, Puri GD, Arun D, Chakravarty V, Aveek J, Chari P. Assessment of intraoperative blood transfusion practice during elective non-cardiac surgery in an Indian tertiary care hospital. $\mathrm{Br} \mathrm{J}$ Anaesth 2003; 91: 586-9

24. Mollison PL. Blood transfusion in clinical medicine. Oxford, Blackwell Scientific, 2005.

25. McFarland W, Mvere D, Shandera W, Reingold A: Epidemiology and prevention of transfusionassociated human immunodeficiency virus transmission in sub-Saharan Africa. Vox Sang 1997; 72: 85-92.

26. Dzik WH, Emily Cooley Lecture 2002: transfusion safety in the hospital. Transfusion 2003; 43: 1190-9..

27. Maclennan S, Murphy MF. Survey of the use of whole blood in current blood transfusion practice. Clin Lab Haematol 2001; 23: 391-6

28. Special Focus: Blood Safety and Rational Use of Blood Indian Journal for the Practising DoctorAuthor(s): Farooq Fazili, MDVol. 3, No. 1 (200603 - 2006-04)

29. Rational use of blood components - an audit Minal Wade, Ratna Sharma, and Mamta Manglani. Indian J Hematol Blood Transfus. 2009 June; 25(2): 66-69. 